\title{
Robotic-assisted surgery for esophageal submucosal tumors: a single-center case series
}

\author{
Caterina Froiio ${ }^{1,2}$ - Felix Berlth ${ }^{1} \cdot$ Giovanni Capovilla $^{1}$. Evangelos Tagkalos ${ }^{1}$. Edin Hadzijusufovic ${ }^{1} \cdot$ Carolina Mann $^{1}$. \\ Hauke Lang ${ }^{1} \cdot$ Peter Philipp Grimminger ${ }^{1}$
}

Received: 15 October 2021 / Accepted: 15 January 2022 / Published online: 11 February 2022

(c) The Author(s) 2022

\begin{abstract}
Esophageal submucosal tumors (SMTs) are rare heterogenous clinical entities. The surgical resection can be performed in different surgical approaches. However, the robotic surgical strategy is poorly documented in the treatment of SMTs. We present our series of operated esophageal SMTs approached via robotic-assisted surgery. Six patients with symptomatic esophageal submucosal tumors underwent robotic surgery within a 3-year period. The performed procedures were robotic-assisted enucleation, robotic esophagectomy (RAMIE) and reverse hybrid robotic esophagectomy. Patients' clinical data, intra/postoperative outcomes, and histopathological features were retrieved from the institution's prospective database. Five of six patients were scheduled for upfront surgery: four underwent robotic enucleation (three leiomyoma and one suspected GIST) and one underwent reverse hybrid robotic esophagectomy (suspected GIST). One patient, diagnosed with GIST, was treated with neoadjuvant Imatinib therapy, before undergoing a RAMIE. No major intra-operative complications were recorded. Median length of stay was 7 days (6-50), with a longer post-operative course in patients who underwent esophagectomy. Clavien-Dindo $>3$ a complications occurred in two patients, aspiration pneumonia and delayed gastric emptying. The final histopathological and immuno-histochemical diagnosis were leiomyoma, well-differentiated GIST, low-grade fibromyxoid sarcoma and Schwannoma. Robotic-assisted surgery seems to be a promising option for surgical treatment strategies of benign or borderline esophageal submucosal tumors.
\end{abstract}

Keywords Esophageal submucosal tumor $\cdot$ SMTs $\cdot$ Robotic enucleation $\cdot$ Robotic-assisted minimally invasive esophagectomy

\section{Introduction}

Esophageal submucosal tumors (SMTs) are rare, accounting for less than $1 \%$ of all esophageal neoplasms [1]. They arise from mesenchymal, muscle, vascular, nerve or glandular cells, defining a histopathological heterogeneous group of tumors with different clinical implications. Despite being more frequently benign lesions (e.g., leiomyoma, lipoma), they may also show borderline or malignant clinical behavior (e.g., GIST, sarcoma) [2-4]. If symptomatic, the most

Peter Philipp Grimminger

peter.grimminger@unimedizin-mainz.de

1 Mainz University, Johannes Gutenberg Universitat Mainz, Mainz, Germany

2 Department of General Surgery, IRCCS Policlinico San Donato, University of Milan, Milano, Italy frequent clinical manifestation is dysphagia, related to the size of the tumor.

Neither endoscopic nor radiological imaging techniques can always deliver an accurate clinical differential diagnosis between benign and malignant lesions, and the pre-operative histopathological definition is not always conclusive [5]. This challenge, combined with the low incidence of SMTs leads to a non-standardized management in terms of diagnostic and therapeutic treatment pathways.

Surgical resection of esophageal submucosal tumors (enucleation, resection up to subtotal esophagectomy), represents the mainstay in the treatment of suspected malignant tumors and of large symptomatic lesions [6-8].

Minimally invasive surgery including a thoracoscopic surgical approach is established in the treatment of esophageal diseases and offers the advantages of a shorter hospitalization and a faster recovery, compared to open surgery. A robotic-assisted approach, with high-definition 3-d vision 
and a 7-degree articulation of the instruments could significantly improve the surgeon's ability to manage difficult anatomical features in a narrow space such as the thoracic cavity, overcoming the weakness of thoracoscopy in the management of complex cases.

In this case series, we present a series of submucosal esophageal tumor approached with different techniques via robotic-assisted esophageal surgery.

\section{Materials and methods}

We conducted a retrospective review of all consecutive patients referred to our Institute for SMTs of the esophagus, including both benign and borderline tumors, that underwent robotic-assisted surgical treatment.

Patient's preoperative data, intraoperative and post-operative outcomes were retrieved from the institution`s prospective database. Demographic and clinical data included sex, age, BMI, ASA score, Charlson Comorbidity Index, clinical presentation, location and size of the lesions, and preoperative histologic features.

Diagnostic preoperative work-up included flexible endoscopy, endoscopic ultrasound-guided fine-needle aspiration (EUS-FNA), and chest and abdominal contrast-enhanced computed tomography (CT-Scan). The positron emission tomography (PET-CT) was performed only in patients with clinical suspicious of malignant tumors. Indication for surgery included the preoperative diagnosis of GIST in three cases (50\%) and the symptomatic increasing tumor size in the other cases. One patient with the preoperative diagnosis of GIST, requiring multi-modal treatment, was treated with neoadjuvant imatinib chemotherapy, according to final decision of multidisciplinary tumor board.

Post-operative complications were graded according to the Clavien-Dindo classification [9]. Histological and immuno-histochemical characteristics of the tumors were also reviewed.

Continuous variables were described as mean (range) and median (IQR), while categorical variables were described using frequencies and percentages.
All procedures were conducted in accordance with the ethical standards and with the Helsinki Declaration. Informed consent was not required due to the retrospective design of the study.

\section{Surgical technique}

\section{Surgical position}

All procedures were performed with DaVinci $\mathrm{Xi}^{\circledR}$ System (Intuitive Surgical Inc. Sunnyvale, CA, USA). A doublelumen endotracheal tube was used to obtain single-lung ventilation for the thoracic phase. The patients were placed in a left lateral semi-prone position (with the $\square$ operation table tilted $30^{\circ}$ toward prone) and patient's right arm was raised cranially. The DaVinci $\mathrm{Xi}^{\circledR}$ System was placed on the patient's right side and the assistant surgeon was located on

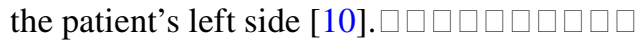

\section{Robotic enucleation}

The three robotic trocars were placed in the following positions (Fig. 1a): the $8 \mathrm{~mm}$ camera trocar along the posterior axillary line in 6th intercostal space (ICS); the $8 \mathrm{~mm}$ "righthand" trocar at the posterior axillary line in 4th ICS; the $8 \mathrm{~mm}$ "left-hand" trocar in posterior axillary line in 8th ICS; and an assistant laparoscopic $12 \mathrm{~mm}$ trocar was placed along the anterior axillary line in the 7th ICS. A mild pneumothorax was induced using a pressure of $7 \mathrm{mmHg}$. The DaVinci $\mathrm{Xi}^{\circledR}$ System docking was then performed.

After diagnostic thoracoscopy using the DaVinci Xi $8 \mathrm{~mm} 30^{\circ}$ Endoscope, we opened the mediastinal pleura up to $2 \mathrm{~cm}$ above the azygos vein to expose the thoracic esophagus. The placement of a $38 \mathrm{Ch}$ gastric tube was useful to define the extent of the tumor and to preserve the opposite wall of the esophagus. The serosa and the muscular layer were opened by the Permanent Monopolar Cautery Hook placed in right-hand trocar. Subsequent careful enucleation of the tumor was performed through cautious dissection, to protect the mucosa and to avoid the rupture of the lesion.
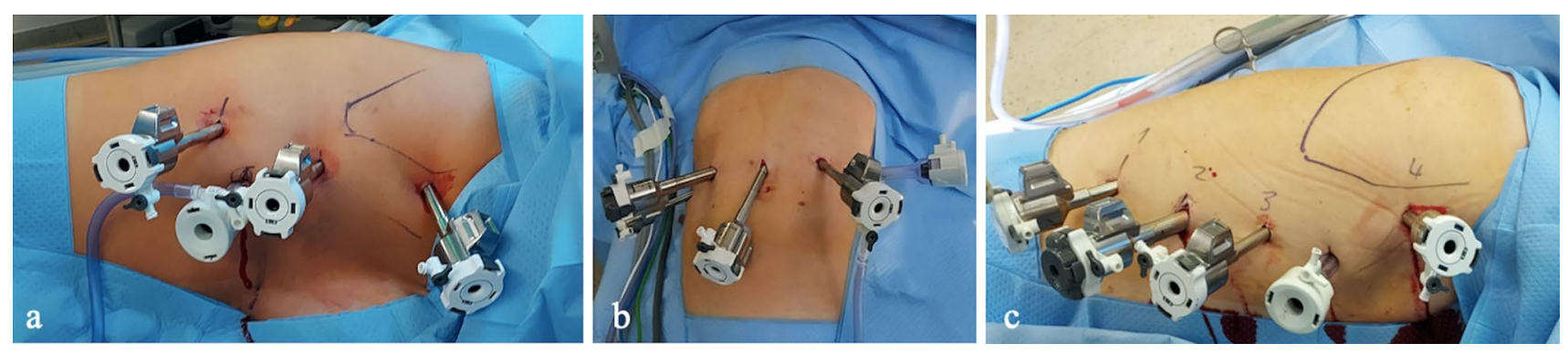

Fig. 1 a Trocar placement for robotic enucleation; $\mathbf{b}$ and trocar placement for abdominal part and thoracic part in RAMIE 
The Bipolar Fenestrated Forceps in the left-hand were used as a retractor. In one patient, the opening of the esophageal mucosa occurred, due to the tenacious adhesion between the mucosa and the muscular layer in the site of a previous EUSFNA, and it was closed using a single PDS 4/0 stich. After recovering the specimen in a bag, the muscular and serosal layers were then approximated with two running V-loc 4/0 sutures (V-Loc ${ }^{\mathrm{TM}}$, Covidien, Mansfield, MA). The esophagus was covered with a pleural tent fixed with V-loc $4 / 0$ or PDS 4/0 running suture. Hemostasis was conducted, when necessary, using the bipolar forceps or the monopolar hook. After undocking the DaVinci $\mathrm{Xi}^{\circledR}$ System, the specimen could be extracted through an enlargement of the assistant $12 \mathrm{~mm}$ trocar. A $20 \mathrm{Ch}$ chest tube was left in the pleural space through the left-hand $8 \mathrm{~mm}$ trocar, the re-expansion of the lung was controlled under vision.

\section{Robotic sub-total esophagectomy}

The surgical procedure was previously extensively described by our group $[10,11]$. We describe it briefly below.

\section{Abdominal part}

For the abdominal part, the patient was in a supine position, and the trocars were placed in a horizontal line at or above the umbilicus as follows (Fig. 1b): an $8 \mathrm{~mm}$ robotic trocar in the right mid-abdomen (trocar 1); a $12 \mathrm{~mm}$ robotic trocar between the umbilicus and trocar 1 (trocar 2, "lefthand trocar"); an $8 \mathrm{~mm}$ camera robotic trocar at or above the umbilicus (trocar 3); an $8 \mathrm{~mm}$ robotic trocar placed 6-8 $\mathrm{cm}$ laterally to the robotic umbilical trocar (trocar 4, "righthand" trocar). One $12 \mathrm{~mm}$ assistant trocar was positioned at the upper left abdominal quadrant. In the abdomen, $\mathrm{CO}_{2}$ insufflation with a $14 \mathrm{mmHg}$ was used. The DaVinci Xi ${ }^{\circledR}$ System docking was then performed. The da Vinci Xi $8 \mathrm{~mm}$ $30^{\circ}$ Endoscope was placed in the trocar 3 . The mobilization of the stomach was performed using the Vessel Sealer Extend $^{\mathrm{TM}}$ or SynchroSeal ${ }^{\mathrm{TM}}$ (Intuitive, Sunnyvale, CA) in the trocar 4, and the Fenestrated Bipolar Forceps (trocar 2) or Tip-up Fenestrated Grasper (trocar 1) was used for retraction; this last one was also used to lift the left lobe of the liver. The creation of a gastric conduit was performed using the robotic SureForm ${ }^{\circledR} 60 \mathrm{~mm}$ stapler (in $12 \mathrm{~mm}$ trocars) starting at the lesser curvature near the crow foot and proceeding with another two 60-mm blue magazines toward the fundus, parallel to the greater curvature; 6 to $7 \mathrm{~cm}$ of stomach were left to complete the gastric conduit in the thoracic part. A Permanent Monopolar Cautery Hook was used for the lymph node dissection (trocar 4), and the EndoWrist ${ }^{\circledR}$ Clip Applier was used to clip the left gastric artery. The assistant trocar was used for suction, retraction, and collection of resected specimens, as lymph nodes.

\section{Thoracic part}

Patient position, DaVinci $\mathrm{Xi}^{\circledR}$ System and assistant surgeon settings were the same described for robotic enucleation.

Trocars were placed as follows (Fig. 1c): the $8 \mathrm{~mm}$ camera trocar was placed between the middle and the anterior axillary line in the 6th ICS; the "right-hand" $8 \mathrm{~mm}$ trocar was placed along the posterior axillary line in the 4th ICS and the "left-hand" $12 \mathrm{~mm}$ trocar was placed along the middle axillary line in the 8th ICS; an $8 \mathrm{~mm}$ trocar was placed in the 10th ICS along the posterior axillary line for retraction; a $12 \mathrm{~mm}$ laparoscopic assistant trocar was placed in the 5th ICS along the anterior axillary line. The dissection of the esophagus and the thoracic 2-Field lymphadenectomy were performed using the Permanent Monopolar Cautery Hook. If needed, the azygos vein was clipped using the EndoWrist ${ }^{\circledR}$ Clip Applier through trocar 4 and transected with the Vessel Sealer. The esophagus was transected above the azygos vein using the monopolar hook. The purse string suture in the esophageal stump was performed robotically using a $90 \mathrm{~cm}$ Prolene 2/0 (Ethicon, USA). Next, the DaVinci Xi system was temporary undocked. The $12 \mathrm{~mm}$ assistant trocar incision was widened to create a mini-thoracotomy, and an Alexis O Wound Retractor (Alexis ${ }^{\mathrm{TM}}$ Laparoscopic System, Applied Medical) was inserted. The thoracotomy was then used to introduce the anvil of the circular stapler $(28 \mathrm{~mm}$ EEA $^{\mathrm{TM}}$, Covidien, Mansfield, MA, USA) and inserted it in the esophageal stump. The specimen was pulled toward the mediastinum, exteriorized through the mini-thoracotomy, and opened to insert the circular stapler into the stomach. The stapler was then pushed into the chest and the circular anastomosis was performed. The da DaVinci $\mathrm{Xi}^{\circledR}$ System was docked again to complete the final step in stapling the rest of the gastric conduit with the $60 \mathrm{~mm}$ robotic SureForm ${ }^{\circledR}$ stapler; a thick 38-ch gastric tube was introduced into the gastric conduit to prevent its narrowing. Then, the specimen was completely stapled and retrieved. We usually reinforce the circular anastomosis with 2 hemicircumferential running sutures, using 2 barbed monofilament absorbable stitches (V-Loc ${ }^{\mathrm{TM}}$, Covidien, Mansfield, MA). Hemostasis was conducted, when necessary, using the bipolar forceps or the energy device (Vessel Sealer Extend $^{\mathrm{TM}}$ or SynchroSeal ${ }^{\mathrm{TM}}$, Intuitive, Sunnyvale, CA). One chest drain was inserted via the robotic trocar at ICS 10 after undocking the robot. 


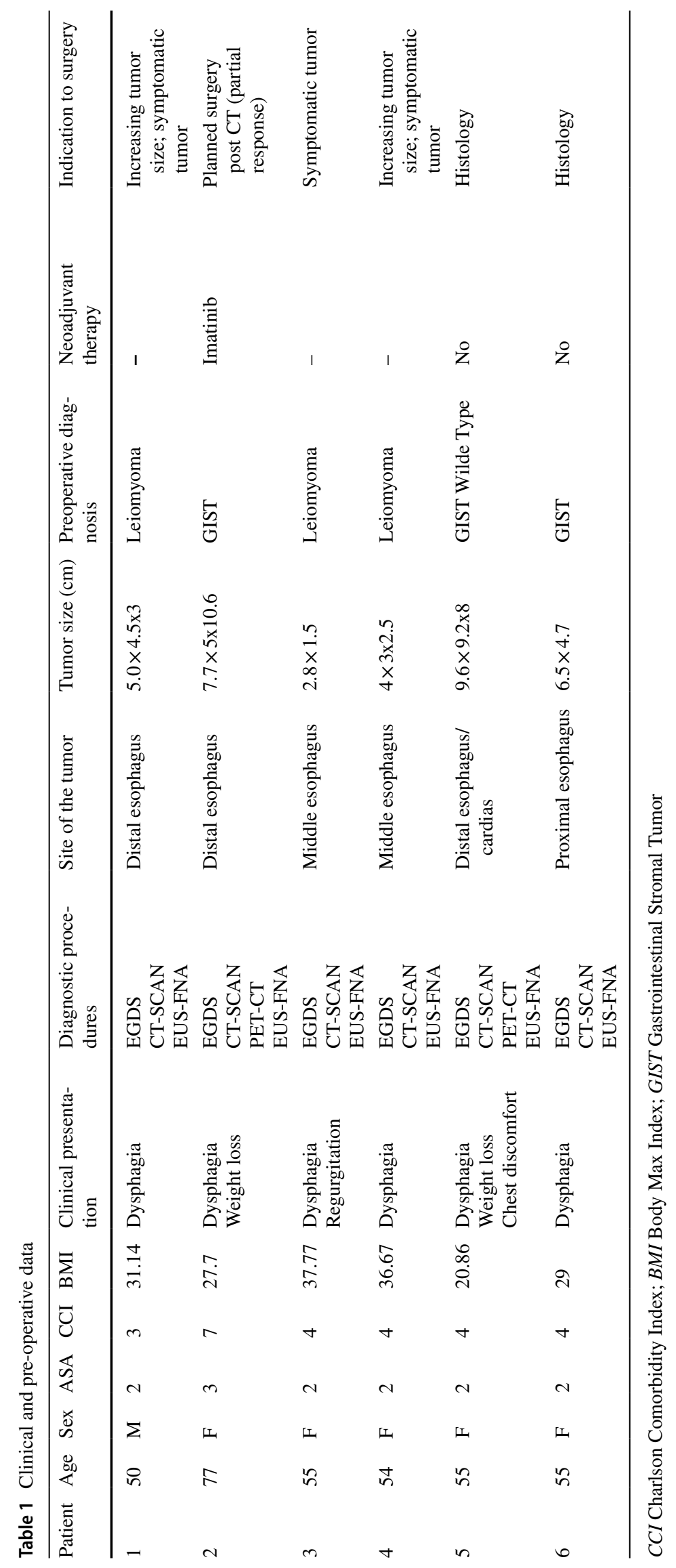


Fig. 2 Endoscopic view of a GIST and b Schwannoma
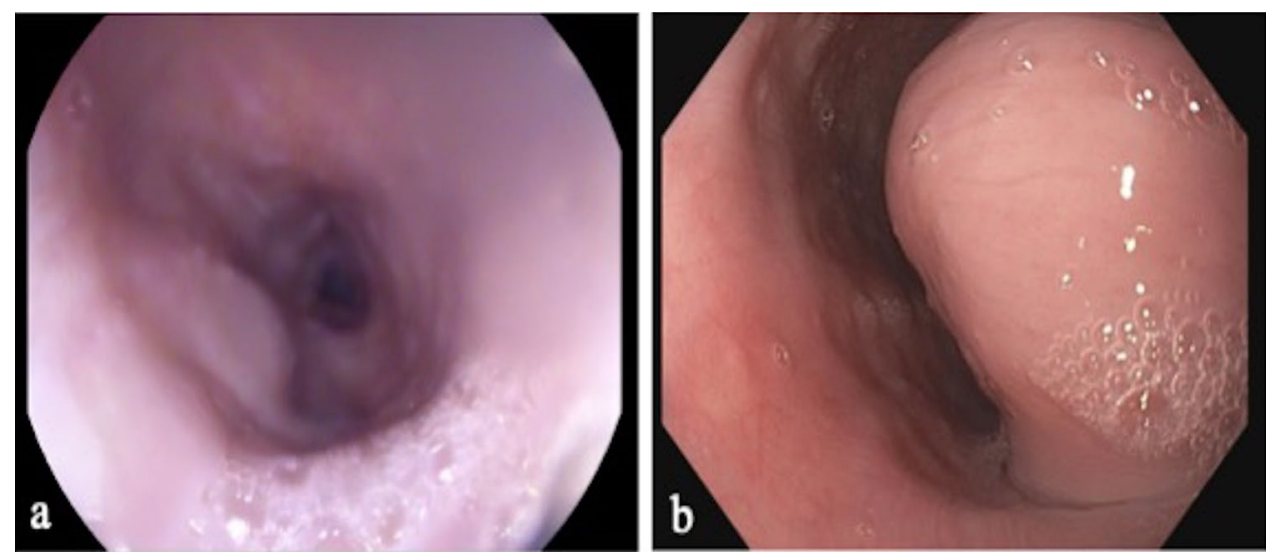

Fig. 3 a leiomyoma of the distal esophagus; $\mathbf{b}$ GIST of the distal esophagus; c low-grade fibromyxoid sarcoma of the distal esophagus; d Schwannoma of the proximal esophagus
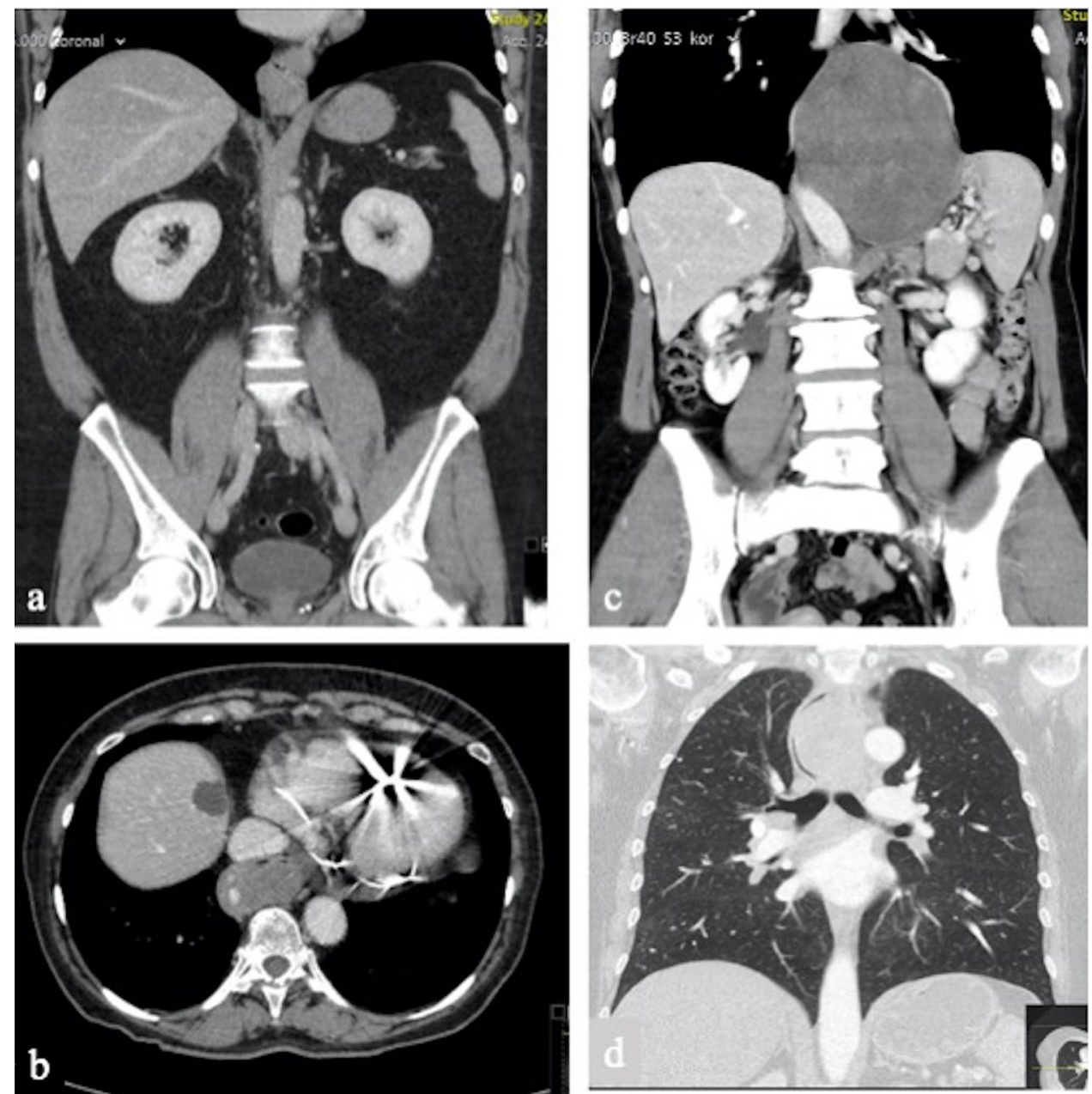

\section{Reverse Robotic Hybrid esophagectomy}

This surgical procedure consisted of a primary thoracic robotic phase, a subsequent abdominal laparotomy phase for the resection of the large tumor mass (see CT scan Fig. 3), followed by the robotic thoracic phase to perform the Ivor
Lewis esophagectomy and intrathoracic esophagogastric anastomosis.

The thoracic phase was described above: with the patient in a left semi-prone position and single-lung ventilation, the da DaVinci $\mathrm{Xi}^{\circledR}$ System was docked. After mobilizing the esophagus, a standard thoracic lymphadenectomy was performed, the esophagus was stapled using EndoGia ${ }^{\mathrm{TM}}$ stapler 
Fig. 4 Intraoperative findings: $\mathbf{a}$ and $\mathbf{b}$ enucleation of a leiomyoma of the middle esophagus, (the azygos vein is sectioned between Hem-oLock); c leiomyoma of the distal esophagus; d Schwannoma of the proximal esophagus; e giant low-grade fibromyxoid sarcoma of the distal esophagus; $\mathbf{f}$ the esophagus is covered with a pleural tent fixed with V-loc 4.0 running suture
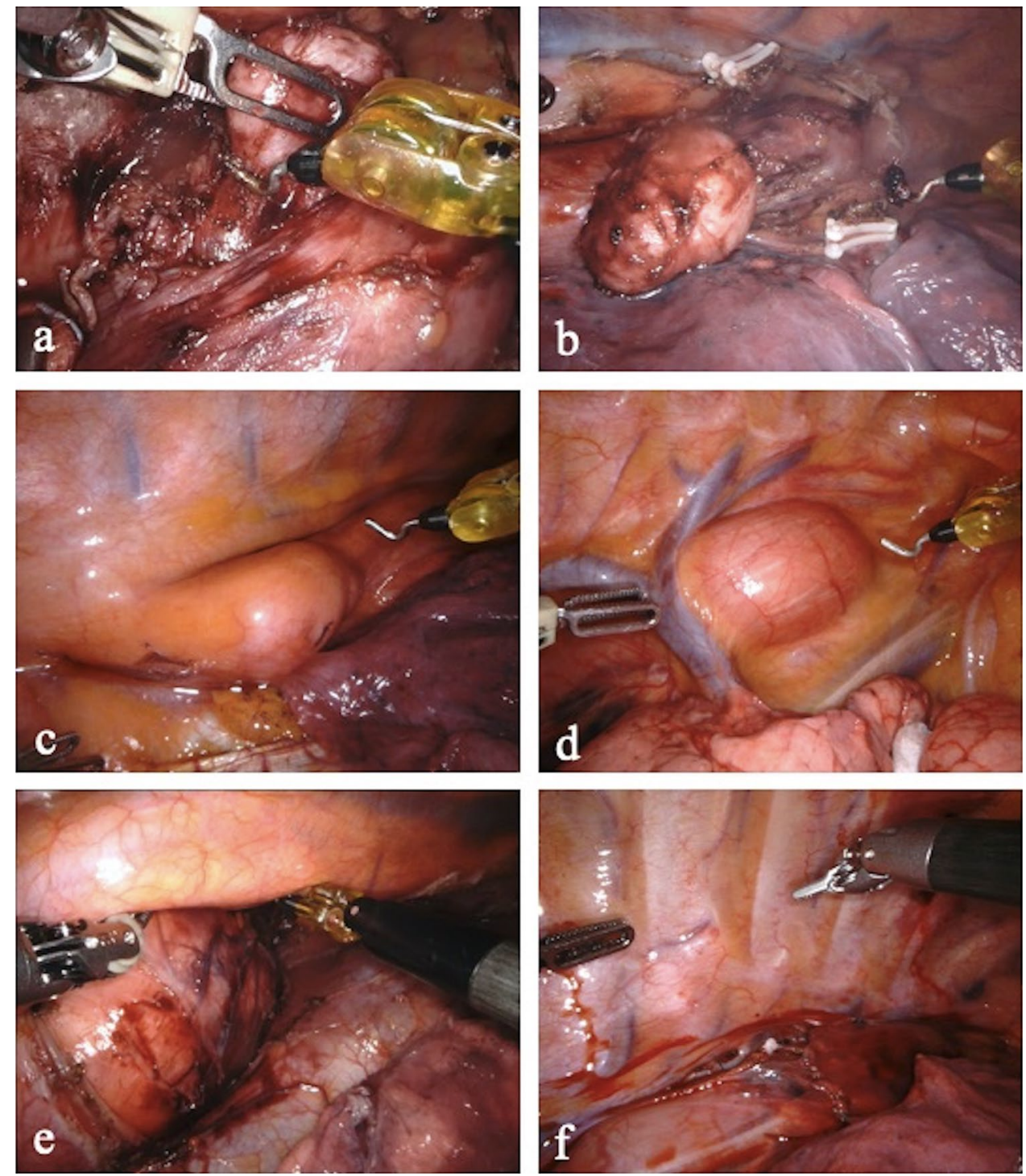

(45 mm purple, Covidien, Mansfield, MA, USA). The azygos vein and the thoracic duct were preserved.

The patient was then placed in a supine position. Through a median supra-umbilical laparotomy, the gastro-lysis and standard lymphadenectomy were carried out. The gastric conduit was created using an EndoGia ${ }^{\mathrm{TM}}$ stapler (45 mm purple, Covidien, Mansfield, MA, USA), starting at the lesser curvature toward the fundus, parallel to the greater curvature. In this case, the conduit was completely separated from the remaining portion of the stomach. The specimen could thus be retrieved through the diaphragmatic hiatus and be sent for definitive histological examination. The gastric conduit was then transposed in the mediastinum, and a posterior hiatoplasty was performed.

The patient was repositioned on the semi-prone left side with a mild pneumothorax. The esophagus was opened at the level of the previous suturing line and, through a $4 \mathrm{~cm}$ mini-thoracotomy along the $12 \mathrm{~mm}$ assistant trocar, the anvil of a circular stapler (28 mm EEA ${ }^{\mathrm{TM}}$, Covidien, Mansfield, MA, USA) was inserted into the esophageal stump. After choosing the site for the anastomosis, at the greater curvature, the intrathoracic circular-stapled anastomosis with reinforcement of the pleural flap was performed, as described above. The remaining part of the stomach was stapled with an EndoGia ${ }^{\mathrm{TM}}$ stapler (60 mm purple, Covidien, Mansfield, MA, USA) and retrieved. A 20 Ch chest drain was placed in the pleural space through the lowest left 8-mm trocar.

\section{Results}

Six patients with esophageal submucosal tumors were robotically operated over a 3 -year period. The preoperative and clinical data, including concomitant tumor's characteristics and indication to surgery, are summarized in Table 1. 


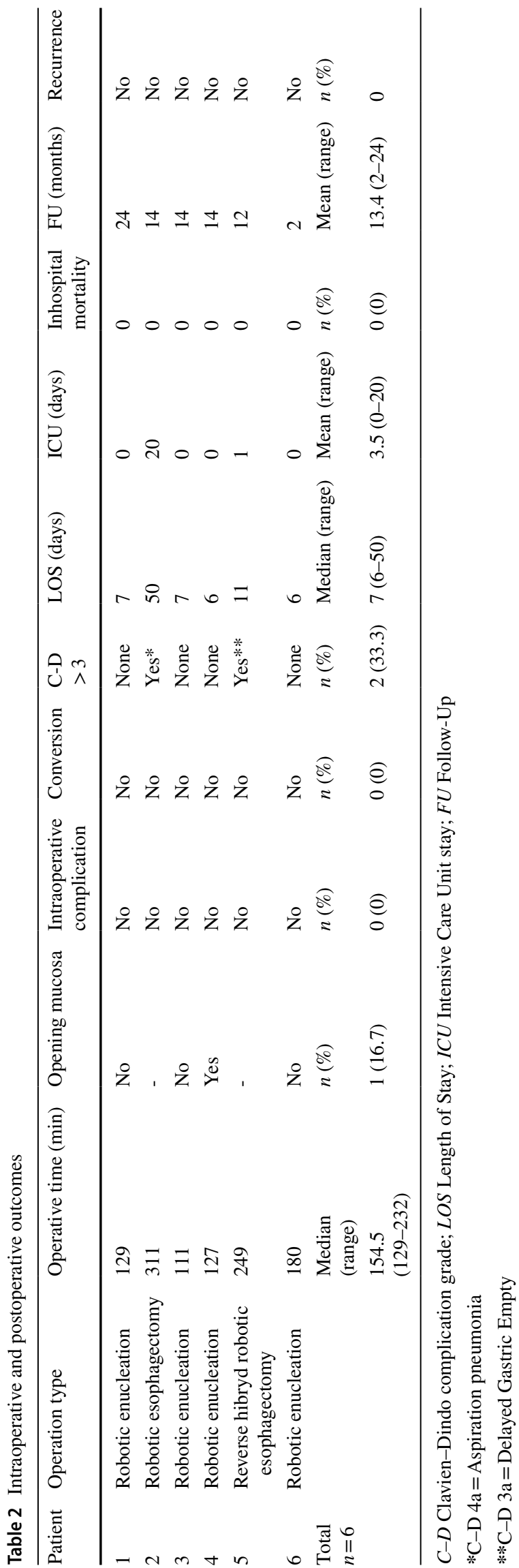

The mean age was 57.3 years (range $50-77$ ) and male to female ratio was 1:5. The most frequent clinical presentation was dysphagia (100\%), other referred symptoms were weight loss ( 2 of 6 patients; $33.3 \%$ ), chest discomfort (1 of 6 patients; 16.7\%) and regurgitation (1 of 6 patients; $16.7 \%)$. The diagnosis of a submucosal esophageal tumor was made through endoscopy in all patients (Fig. 2). The lesions were distributed at the proximal esophagus ( 1 of 6 patients; $16.7 \%$ ), at the middle esophagus ( 2 of 6 patients; $33.3 \%$ ) and at the distal esophagus (3 of 6 patients; 50\%). All patients underwent chest-abdominal contrast-enhanced CT scan (Fig. 3). Two patients with suspicious malignant lesions underwent PET-CT, that in both cases did not show specific FDG avidity. No distant lesions suspected of malignancy were found in any patient. Ultrasound endoscopy was performed in all patients, confirming the submucosal origin of the tumors, and a FineNeedle Aspiration (EUS-FNA) for cytochemical diagnosis was performed. The preoperative histologic diagnosis was leiomyoma in three patients (50\%), GIST in two patients $(33.3 \%)$ and GIST Wilde Type in one patient (16.7\%).

Among patients diagnosed with GIST, two underwent upfront surgery and one patient, according to the final decisions of multidisciplinary tumor board, was referred to a neoadjuvant treatment with Imatinib. The subsequently revaluation resulted in a partial regression of the tumor and the patient was then scheduled for surgery. The choice of surgical strategies took into account the location of the tumor, the preoperative histological diagnosis and the size of the lesion. The surgical procedures included robotic enucleation (leiomyoma or small GIST), robotic Ivor Lewis esophagectomy (RAMIE) with 2-Field lymphadenectomy (GIST); and hybrid robotic reverse esophagectomy with a 2-Field lymphadenectomy (robotic thorax phase and laparotomic abdominal phase; suspected GIST), due to the large size of the lesion involving the abdominal cavity. The Fig. 4 shows the intraoperative findings.

Intra-operative and post-operative outcomes are reported in Table 2. All the procedures were completed by the planned robotic approach, without conversion. No major intraoperative complications, such us bleeding, airway injuries, vascular injury, inability to maintain singlelung ventilation, occurred. We recorded only one case of esophageal mucosa opening, due to previous biopsy. The dissection of tumors was carried out en bloc, maintaining the capsule integrity in all cases. The median duration of surgery was $154.5 \mathrm{~min}$.

We observed two cases of postoperative Clavien-Dindo > 3a complications: one patient suffered from aspiration pneumonia and subsequent respiratory failure, that required reintubation and referral to the intensive care unit; one patient experienced a delayed gastric empty treated by endoscopic dilatation of the pylorus. 
Table 3 Immuno-histopathological staining and pathological diagnosis of the tumor

\begin{tabular}{|c|c|c|c|c|c|c|c|c|c|c|c|}
\hline Patient & c-Kit & DOG-1 & Desmin & S-100 & SMA & CD34 & ALK-1 & STAT-6 & $\mathrm{Ki}-67$ & $\begin{array}{l}\text { Mito- } \\
\text { sis/50 } \\
\text { HPF }\end{array}$ & Definitive diagnosis \\
\hline 1 & & - & + & $\mathrm{nt}$ & + & nt & $\mathrm{nt}$ & $\mathrm{nt}$ & $2 \%(\mathrm{MIB}-1)$ & - & Leiomyoma \\
\hline 2 & + & + & $\mathrm{nt}$ & $\mathrm{nt}$ & $\mathrm{nt}$ & $\mathrm{nt}$ & $\mathrm{nt}$ & $\mathrm{nt}$ & $10 \%$ & 2 & $\begin{array}{l}\text { GIST } \\
\text { EXON-9 mutation* }\end{array}$ \\
\hline 3 & - & - & + & $\mathrm{nt}$ & + & nt & $\mathrm{nt}$ & $\mathrm{nt}$ & $<1 \%$ & - & Leiomyoma \\
\hline 4 & - & - & + & $\mathrm{nt}$ & + & - & $\mathrm{nt}$ & $\mathrm{nt}$ & $<1 \%$ & - & Leiomyoma \\
\hline 5 & - & - & - & - & - & - & - & - & $1-2 \%$ & 2 & $\begin{array}{l}\text { Low-grade fibro- } \\
\text { myxoid sar- } \\
\text { coma** }\end{array}$ \\
\hline 6 & - & - & - & + & - & - & - & nt & $5 \%$ & 1 & Schwannoma** \\
\hline
\end{tabular}

$n t$ not tested

* Molecular analysis by PCR (polymerase chain reaction)

**Definitive diagnosis differs from the preoperative one

The median postoperative length of stay was 7 days (6-50). There was no in-hospital mortality. At a mean follow-up of 13.4 months (2-24), all patients were alive with no detectable recurrence.

Definitive postoperative histopathologic and immunohistochemical characterization confirmed the pre-operative diagnosis of leiomyoma in all cases. Among patients with preoperative diagnosis of GIST, confirmation was only found in one case, while in the other two cases, the final diagnoses were low-grade fibromyxoid sarcoma and Schwannoma (Table 3). All procedures were carried out as R0 resection.

\section{Discussion}

Since the low incidence of the esophageal SMTs [1-3], a standardization in their clinical management is difficult.

We reported our case series of esophageal SMTs approached via robotic-assisted surgery, describing the surgical technical details, the intraoperative and postoperative outcomes. Considering the high morbidity and mortality associated to esophageal surgery $[12,13]$, an adequate diagnostic path is mandatory to select patients for primary surgery and/or neoadjuvant therapy, and for the choice of the most suitable surgical treatment (enucleation vs major resection).

The diagnostic work-up is based on endoscopy and endosonographic features $[3,5,14]$ and radiological investigation as CT scan with contrast enhancement and FDG-PET [15, 16]. The role of preoperative histology with EUS-FNA or cut biopsy is still on debate; biopsies are often inconclusive or inconsistent with final pathological examinations. Furthermore, the procedure is burdened by the risk of tumor dissemination through a capsule interruption and may cause esophageal mucosal damage with subsequently difficult identification of planes during surgical enucleation $[7,8$, 17]. In our series, two of three patients with preoperative diagnosis of GIST resulted in an alternative definitive pathological finding. Furthermore, previous EUS-FNA resulted in the opening of the mucosal layer in one patient.

The choice of the type of operation, enucleation or esophagectomy, depends on the localization, size and suspected malignant behavior of the tumor [5, 18, 19]. Enucleation is widely accepted in case of benign lesions

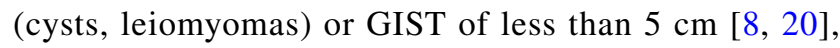
while esophagectomy is preferred as the treatment of choice for larger tumors, localized in challenging positions or highly suspicious for malignancy, such as the presented case no. 5 (Table 1) [18, 19].

The minimally invasive approach as thoracoscopy has brought important advantages in esophageal surgery, such as less blood loss, faster postoperative stay, a shorter recovery and a lower rate of perioperative complications, becoming the preferred surgical approach for such lesions $[4,13,21]$.

Since the first thoracoscopic enucleation of an esophageal leiomyoma, described by Everitt in 1992 [22], this approach has been increasingly chosen from several Authors, who described its feasibility and safety in the treatment of leiomyomas or GISTs [4, 23, 24]. Similarly, prone thoracoscopic esophagectomy has gained acceptance for the treatment of challenging submucosal tumors, characterized by large size or malignant behavior, with favorable short-term and oncological outcomes [25-27].

The advancement of robotic technologies has made it possible to overcome the technical limitations of laparoscopic or thoracoscopic surgery, such as the lack of intra-corporeal articulation of the surgical instruments, and the poor ergonomics of the surgeon in performing complex procedures [28]. The robotic system facilitates technically difficult 


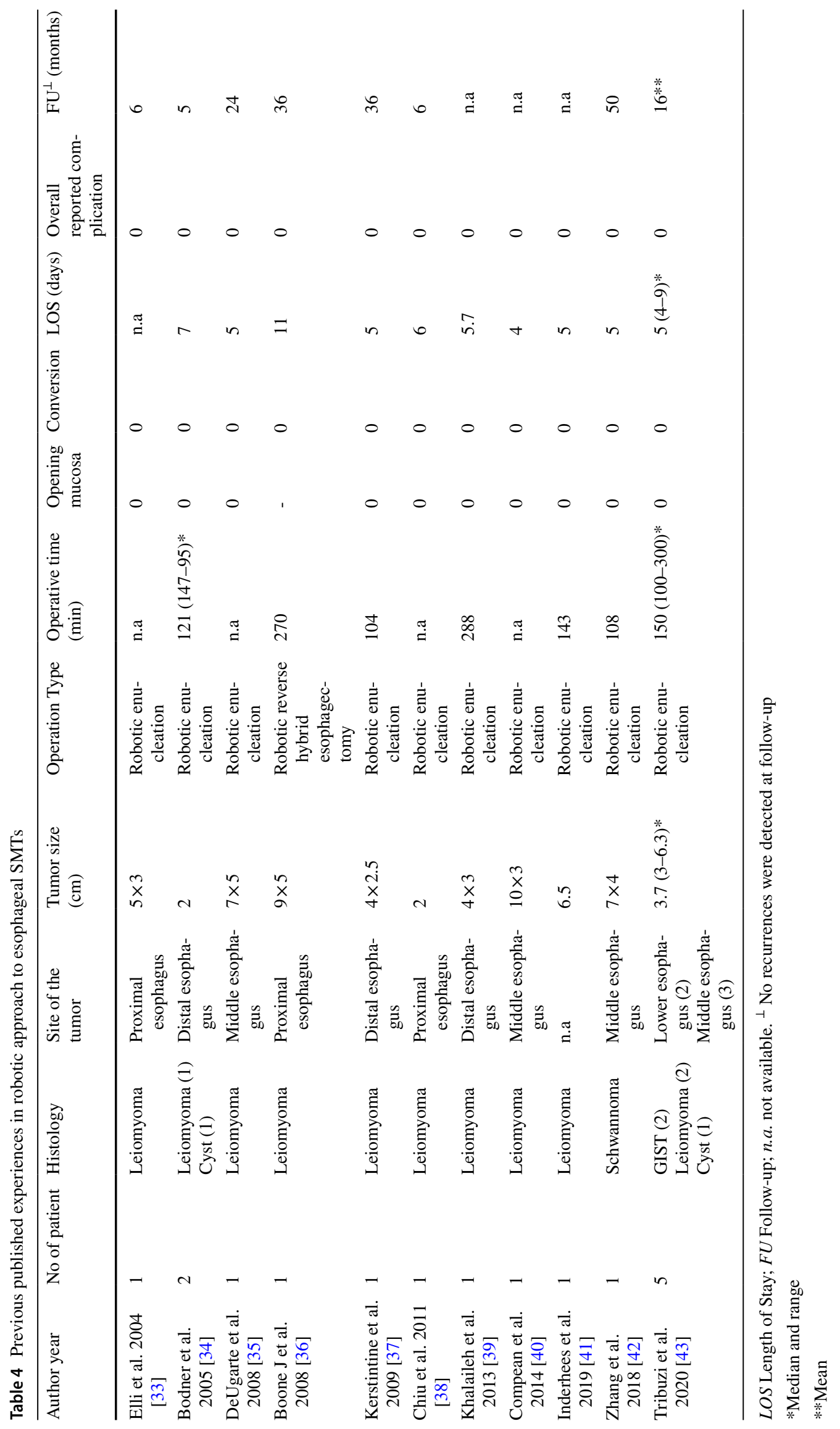


dissections, sutures, and intrathoracic preparation and may prevent esophageal injuries or tumors' rupture during enucleations. The safety and feasibility of the robotic approach for esophageal cancers have been previously described, [29, 30 ] and the intraoperative and postoperative benefits can reasonably be exploited in the treatment of these borderline tumors.

In literature, the safety and feasibility of the robotic approach of mesenchymal tumors has recently been described for the treatment of gastric GIST in unfavorable locations by Arseneaux [31] and Winder [32], showing optimal surgical and oncological outcomes. However, although with satisfactory results, the published experiences concerning the robotic approach to esophageal SMTs are limited to some case reports and only one case series (Table 4). Since the first case of robotic enucleation of two esophageal leiomyomas was described, by Elli [33] in 2004, only few case reports have been reported in the past 15 years, all involving robotic treatment of esophageal leiomyomas [34-41] and one case of Schwannoma [42]. The only case series concerning the treatment of different esophageal SMTs (GIST, leiomyoma and cyst) was recently reported by Tribuzi et al., and the surgical approach consisted only of robotic enucleation [43].

To the best of our knowledge, this is the first series of robot-assisted surgery cases describing the application of several possible approaches (enucleation, RAMIE, ReverseHybrid RAMIE) for esophageal submucosal tumors. Furthermore, we report a heterogenous group of esophageal SMTs, with different clinical behavior, successfully treated regardless of the size, esophageal site and anatomical complexity related to some of them. Our experience of roboticassisted surgery for submucosal esophageal tumors resulted in excellent surgical outcomes without intraoperative complications or need for conversion. In only one patient, we planned a hybrid approach due to the large size of the tumor (Fig. 3c) and its localization. The onset of a mucosal lesion during the enucleation of a voluminous leiomyoma was adequately managed with the help of the precise and articulated robotic instruments. The reported post-operative complications, aspiration pneumonia and delayed gastric empty, is a commonly seen complication after esophagectomy, which is not typically related to robotic surgery.

Robotic-assisted esophageal surgery has been consolidated in recent years in our center, for the treatment of malignant and benign tumors of the esophagus; in this series, we describe as the robotic procedures can be feasible and successfully applied also in the treatment of challenging cases. On the other hand, the lack of an adequate number of described cases in literature does not allow serious comparisons.

This study has of course several limitations due to the limited number of patients. Furthermore, the heterogeneity of the study population and different surgical procedures cannot lead to strong conclusions or guidelines.

\section{Conclusion}

Tumors of the esophageal submucosa represent surgical challenges even for experienced surgeons due to their heterogeneity. Our series show that robotic surgery, performed by a specialized center, may facilitate minimally invasive surgery in the management of complex SMT of the esophagus. We believe that the treatment of esophageal SMTs should be planned individually by experienced esophageal surgeons. More studies including an adequate number of patients are needed to confirm our optimal results.

Author contributions Conceptualization: $\mathrm{CF}, \mathrm{FB}$; Data curation: $\mathrm{CF}$, FB, GC; Writing/original draft preparation: CF, FB; Writing/review and editing: CF, FB, GC, PPG; Supervision: HL, PPG; Visualization and approval: CF, FB, GC, ET, EH, CM, HL, PPG.

Funding Open Access funding enabled and organized by Projekt DEAL.

Data availability The data that support the findings of this study are available from the corresponding author upon reasonable request.

\section{Declarations}

Conflict of interest The authors did not receive support from any organization for the submitted work. No funding was received to assist with the preparation of this manuscript. No funding, grants or other support was received for conducting this study. The authors CF, FB, GC, ET, EH, CM, HL have not conflict of interest or financial ties to disclose. PPG is proctor for Intuitive, Sunnyvale, CA.

Ethical approval All procedures were conducted in accordance with the ethical standards and with the Helsinki Declaration.

Informed consent Informed consent was not required due to the retrospective design of the study.

Open Access This article is licensed under a Creative Commons Attribution 4.0 International License, which permits use, sharing, adaptation, distribution and reproduction in any medium or format, as long as you give appropriate credit to the original author(s) and the source, provide a link to the Creative Commons licence, and indicate if changes were made. The images or other third party material in this article are included in the article's Creative Commons licence, unless indicated otherwise in a credit line to the material. If material is not included in the article's Creative Commons licence and your intended use is not permitted by statutory regulation or exceeds the permitted use, you will need to obtain permission directly from the copyright holder. To view a copy of this licence, visit http://creativecommons.org/licenses/by/4.0/. 


\section{References}

1. Postlethwait RW, Wendell Musser A (1974) Changes in the esophagus in 1,000 autopsy specimens. J Thorac Cardiovas Surg. https://doi.org/10.1016/s0022-5223(19)39690-4

2. Seremetis MG, Lyons WS, Deguzman VC, Peabody JW (1976) Leiomyomata of the esophagus. An analysis of 838 cases. Cancer. https://doi.org/10.1002/1097-0142(197611)38:5\%3c2166::AIDCNCR2820380547\%3e3.0.CO;2-B

3. Codipilly DC, Fang H, Alexander JA, Ravi KDA (2018) Subepithelial esophageal tumors: a single-center review of resected and surveilled lesions. Gastrointest Endosc 87:370-377. https://doi. org/10.1016/J.GIE.2017.07.043

4. Shin S, Choi YS, Shim YM, Kim HK, Kim K, Kim J (2014) Enucleation of esophageal submucosal tumors: a single institution's experience. Ann Thorac Surg 97:454-459. https://doi.org/ 10.1016/J.ATHORACSUR.2013.10.030

5. Aoki T, Nakamura T, Oshikiri T et al (2018) Strategy for esophageal non-epithelial tumors based on a retrospective analysis of a single facility. Esophagus 15:286-293. https://doi.org/10.1007/ S10388-018-0628-6

6. Bonavina L, Segalin A, Rosati R, Pavanello M, Peracchia A (1995) Surgical therapy of esophageal leiomyoma. J Am Coll Surg 181:257-262

7. Hihara J, Mukaida H, Hirabayashi N (2018) Gastrointestinal stromal tumor of the esophagus: current issues of diagnosis, surgery and drug therapy. Transl Gastroenterol Hepatol. https://doi.org/ 10.21037/TGH.2018.01.06

8. Demetri GD, von Mehren M, Antonescu CR et al (2010) NCCN Task Force report: update on the management of patients with gastrointestinal stromal tumors. J Natl Compr Canc Netw 8(Suppl):2. https://doi.org/10.6004/JNCCN.2010.0116

9. Dindo D, Demartines N, Clavien P-A (2004) Classification of surgical complications. Ann Surg. https://doi.org/10.1097/01.sla. 0000133083.54934.ae

10. Grimminger PP, Hadzijusufovic E, Babic B, van der Sluis PC, Lang H (2020) Innovative fully robotic 4-arm Ivor Lewis esophagectomy for esophageal cancer (RAMIE4). Dis Esophagus Off J Int Soc Dis Esophagus. https://doi.org/10.1093/DOTE/ DOZ015

11. Berlth F, Mann C, Uzun E, Tagkalos E, Hadzijusufovic E, van Hillegersberg R, Li H, Egberts JH, Lang H, Grimminger PP (2020) Technical details of the abdominal part during full roboticassisted minimally invasive esophagectomy. Dis Esophagus Off J Int Soc Dis Esophagus. https://doi.org/10.1093/DOTE/DOAA084

12. Oshikiri T, Takiguchi G, Miura S et al (2018) Current status of minimally invasive esophagectomy for esophageal cancer: is it truly less invasive? Ann Gastroenterol Surg 3:138-145. https:// doi.org/10.1002/AGS3.12224

13. Yibulayin W, Abulizi S, Lv H, Sun W (2016) Minimally invasive oesophagectomy versus open esophagectomy for resectable esophageal cancer: a meta-analysis. World J Surg Oncol. https:// doi.org/10.1186/S12957-016-1062-7

14. Pesenti C, Bories E, Caillol F et al (2019) Characterization of subepithelial lesions of the stomach and esophagus by contrastenhanced EUS: a retrospective study. Endosc Ultrasound 8:43-49. https://doi.org/10.4103/EUS.EUS_89_17

15. Zhang FB, Shi HC, Shu YS, Shi WP, Lu SC, Zhang XY, Tu SS (2015) Diagnosis and surgical treatment of esophageal gastrointestinal stromal tumors. World J Gastroenterol 21:5630-5634. https://doi.org/10.3748/WJG.V21.I18.5630

16. Park JW, Cho CH, Jeong DS, Chae HD (2011) Role of F-fluoro2-deoxyglucose positron emission tomography in gastric GIST: predicting malignant potential pre-operatively. J Gastric Cancer 11:173-179. https://doi.org/10.5230/JGC.2011.11.3.173
17. Dumonceau JM, Deprez PH, Jenssen C et al (2017) Indications, results, and clinical impact of endoscopic ultrasound (EUS)guided sampling in gastroenterology: European Society of Gastrointestinal Endoscopy (ESGE) Clinical Guideline - Updated January 2017. Endoscopy 49:695-714. https://doi.org/10. 1055/S-0043-109021

18. Pence K, Correa AM, Chan E, Khaitan P, Hofstetter W, Kim MP (2017) Management of esophageal gastrointestinal stromal tumor: review of one hundred seven patients. Dis Esophagus Off J Int Soc Dis Esophagus. https://doi.org/10.1093/DOTE/DOX064

19. Coccolini F, Catena F, Ansaloni L, Lazzareschi D, Pinna AD (2010) Esophagogastric junction gastrointestinal stromal tumor: resection vs enucleation. World J Gastroenterol 16:4374-4376. https://doi.org/10.3748/WJG.V16.I35.4374

20. Robb WB, Bruyere E, Amielh D et al (2015) Esophageal gastrointestinal stromal tumor: is tumoral enucleation a viable therapeutic option? Ann Surg 261:117-124. https://doi.org/10.1097/SLA. 0000000000000505

21. Burdall OC, Boddy AP, Fullick J, Blazeby J, Krysztopik R, Streets C, Hollowood A, Barham CP, Titcomb D (2015) A comparative study of survival after minimally invasive and open oesophagectomy. Surg Endosc 29:431-437. https://doi.org/10. 1007/S00464-014-3694-4

22. Everitt NJ, Glinatsis M, McMahon MJ (1992) Thoracoscopic enucleation of leiomyoma of the oesophagus. Br J Surg 79:643-643. https://doi.org/10.1002/BJS.1800790715

23. von Rahden BHA, Stein HJ, Feussner H, Siewert JR (2004) Enucleation of submucosal tumors of the esophagus: minimally invasive versus open approach. Surg Endosc 18:924-930. https://doi. org/10.1007/S00464-003-9130-9

24. Milito P, Asti E, Aiolfi A, Zanghi S, Siboni S, Bonavina L (2019) Clinical outcomes of minimally invasive enucleation of leiomyoma of the esophagus and esophagogastric junction. J Gastrointest Surg 24(3):499-504. https://doi.org/10.1007/S11605-019-04210-3

25. Nguyen NT, Reavis KM, El-Badawi K, Hinojosa MW, Smith BR (2008) Minimally invasive surgical enucleation or esophagogastrectomy for benign tumor of the esophagus. Surg Innov 15:120-125. https://doi.org/10.1177/1553350608317353

26. Kent M, d'Amato T, Nordman C, Schuchert M, Landreneau R, Alvelo-Rivera M, Luketich J (2007) Minimally invasive resection of benign esophageal tumors. J Thorac Cardiovasc Surg 134:176-181. https://doi.org/10.1016/J.JTCVS.2006.10.082

27. Daiko H, Fujita T, Ohgara T, Yamazaki N, Fujii S, Ohno Y, Yano T (2015) Minimally invasive hybrid surgery combined with endoscopic and thoracoscopic approaches for submucosal tumor originating from thoracic esophagus. World J Surg Oncol. https://doi.org/10.1186/S12957-015-0452-6

28. Vereczkel A, Bubb H, Feussner H (2003) Laparoscopic surgery and ergonomics: it's time to think of ourselves as well. Surg Endosc 17:1680-1682. https://doi.org/10.1007/ S00464-003-9020-1

29. van der Sluis PC, van der Horst S, May AM et al (2019) Robotassisted minimally invasive thoracolaparoscopic esophagectomy versus open transthoracic esophagectomy for resectable esophageal cancer: a randomized controlled trial. Ann Surg 269:621-630. https://doi.org/10.1097/SLA.0000000000003031

30. Ruurda JP, van der Sluis PC, van der Horst S, van Hilllegersberg R (2015) Robot-assisted minimally invasive esophagectomy for esophageal cancer: a systematic review. J Surg Oncol 112:257265. https://doi.org/10.1002/jso.23922

31. Arseneaux M, Yarbrough D, Nagamoto T (2019) Roboticassisted free-handed, full-thickness gastric GIST resection with primary repair in unfavorable locations. J Robot Surg 13:491494. https://doi.org/10.1007/S11701-018-0876-4

32. Winder A, Strauss DC, Jones RL, Benson C, Messiou C, Chaudry MA, Smith MJ (2020) Robotic surgery for gastric 
gastrointestinal stromal tumors: a single center case series. J Surg Oncol 122:691-698. https://doi.org/10.1002/JSO.26053

33. Elli E, Espat NJ, Berger R, Jacobsen G, Knoblock L, Horgan S (2004) Robotic-assisted thoracoscopic resection of esophageal leiomyoma. Surg Endosc 18(4):713-716. https://doi.org/10. 1007/S00464-003-8829-Y

34. Bodner JC, Zitt M, Ott H, Wetscher GJ, Wykypiel H, Lucciarini P, Schmid T (2005) Robotic-assisted thoracoscopic surgery (RATS) for benign and malignant esophageal tumors. Ann Thorac Surg 80:1202-1206. https://doi.org/10.1016/J.ATHOR ACSUR.2005.03.061

35. DeUgarte DA, Teitelbaum D, Hirschl RB, Geiger JD (2008) Robotic extirpation of complex massive esophageal leiomyoma. J Laparoendosc Adv Surg Tech A 18(2):286-289. https://doi. org/10.1089/LAP.2007.0067

36. Boone J, Draaisma WA, Schipper MEI, Broeders IAMJ, Rinkes IHMB, van Hillegersberg R (2008) Robot-assisted thoracoscopic esophagectomy for a giant upper esophageal leiomyoma. Dis Esophagus 21(1):90-93. https://doi.org/10.1111/J.14422050.2007.00709.X

37. Kerstintine KH, Andersen ES, Falabella A, Ramirez NA, Anderson CA, Beblawi I (2009) Robotic fourth-arm enucleation of an esophageal leiomyoma and review of literature. Innovations (Phila) 4(6):354-357. https://doi.org/10.1097/IMI.0B013E3181 C46218

38. Chiu PK, Chiu PW, Teoh AY, Wong SK, Ng EK (2011) Robotic-assisted thoracoscopic enucleation of esophageal leiomyoma. J Robot Surg 5(3):227-229. https://doi.org/10.1007/ S11701-010-0236-5

39. Khalaileh A, Savetsky I, Adileh M et al (2013) Robotic-assisted enucleation of a large lower esophageal leiomyoma and review of literature. Int J Med Robot 9:253-257. https://doi.org/10. 1002/RCS.1484

40. Compean SD, Gaur P, Kim MP (2014) Robot assisted thoracoscopic resection of giant esophageal leiomyoma. Int J Surg Case Rep 5(12):1132-1134. https://doi.org/10.1016/J.IJSCR.2014.11. 003

41. Inderhees S, Tank J, Stein HJ, Dubecz A (2019) Leiomyoma of the esophagus: a further indication for robotic surgery? Chirurg 90:125-130. https://doi.org/10.1007/S00104-019-0792-9

42. Zhang Y, Han Y, Xiang J, Li H (2018) Robot-assisted enucleation of large dumbbell-shaped esophageal schwannoma: a case report. BMC Surg. https://doi.org/10.1186/S12893-018-0370-Y

43. Tribuzi A, Bencini L, Paolini C, Di Marino M, Coratti A (2021) Robotic enucleation for oesophageal benign and borderline tumours: less is more? Int J Med Robot 17:1-7. https://doi.org/ 10.1002/RCS. 2178

Publisher's Note Springer Nature remains neutral with regard to jurisdictional claims in published maps and institutional affiliations. 